\title{
À beira do fora: grito e experimentum linguae
}

Vinícius Nicastro Honesko

UFPR

\section{Resumo}

O presente ensaio aborda o problema do fora e do grito a partir do pensamento de Maurice Blanchot e alguns de seus interlocutores. Apresenta como o grito pode ser relacionado às possibilidades de pensar a questão da língua. Mostra como uma compreensão do limite da linguagem é tocado por Blanchot em $A$ parte do fogo. Em seguida, analisa a questáo do mistério da linguagem - o há a língua - a partir de certas leituras de Giorgio Agamben e Jean-Luc Nancy. Propóe, também, que as compreensóes de pensamento do fora e de experimentum linguae podem, de alguma maneira, ser ligadas. Por fim, após passar por várias questôes acerca do impossível e da resistência - própria ao humano - no uso da língua, pensa como certa experiência da linguagem enquanto pensamento do fora é ainda a possibilidade de dizer quando tudo parece já ter sido dito.

Palavras-chave: grito; limite da linguagem; pensamento do fora; experimentum linguae.

\begin{abstract}
The present essay approaches the problem of the outside and of the shout from the thought of Maurice Blanchot and some of his interlocutors. It presents how the shout can be related to the possibilities of thinking the question of the language. It shows how Blanchot touches the comprehension of the limit of the language in The work of fire. Thereafter, it analyses the question of the mystery of the language - the there is language - from certain readings of Giorgio Agamben and Jean-Luc Nancy. It also proposes that the comprehensions of thought of the outside and of experimentum linguae can, somehow, be connected. At last, after crossing various propositions concerning the impossible and the resistance - proper of the human - in the use of language, it thinks how some experience of the language as thought of the outside still is a possibility of saying when everything already seems to be said.

Key-words: shout; limit of the language; thought of the outside; experimentum linguae.
\end{abstract}


1. DELEUZE, Gilles. $A$

Dobra: Leibniz e o Barroco,

1991, p. 79.

2. Ibidem, p. 80 .

3. Ibidem, p. 80 .

4. FOUCAULT, Michel.

"O Pensamento do Exterior", 2009, p. 223.

5. Ibidem, p. 223.

6. BLANCHOT, Maurice.

Une Voix Venue d'Ailleurs, 2002, p. 67. Tradução nossa.

7. Em Giorgio Caproni essa Besta também aparece como o inominável, o por trás das palavras (além, para fora das palavras) como a Besta assassina, que só o poeta sabe: "A Besta assassina. / A Besta que ninguém nunca viu. / A Besta que subterraneamente / falsamente mastim - / cada dia te elide. / A Besta que te vivifica e assim te mata... / ..... / Eu só, com um nó na garganta, / sabia. Está atrás da Palavra.” Cf. CAPRONI, Giorgio. A Coisa Perdida. Agamben comenta Caproni, 2011, p. 263.
Les yeux seuls sont encore capables de pousser un cri.

René Char

Gilles Deleuze, em seu livro sobre o Barroco, ao analisar a questáo dos princípios de identidade e de contradição em Leibniz, diz que para o filósofo alemão os princípios parecem-se com gritos, pois "cada um assinala a presença de uma classe de seres, seres que lançam o grito e se fazem reconhecer por esse grito" De fato, não se trata de uma abstenção ou anulação da questão do conhecimento, mas, continua Deleuze,

faz com que conheçamos uma classe de seres, a dos Idênticos, que são seres completos. O princípio de identidade, ou sobretudo de contradição, é somente o grito dos Idênticos e não pode ser abstrato. É um sinal. Os idênticos são indefiníveis em si e talvez incognoscíveis para nós; nem por isso deixam de ter um critério que o princípio nos permite conhecer ou ouvir. ${ }^{2}$

O grito, a interjeição que é o grito, tem a forma rumorosa de um apontar para o fora, na direção do apagamento reflexivo da linguagem (o princípio não dá um conhecimento interior, mas apresenta os Idênticos como seres completos, infinitos por si, em não relaçấo, pois "não há elemento que um possa afirmar e outro negar"3). De outro modo, poderíamos dizer que a linguagem, pensada como "o próprio brilho do exterior" ${ }^{4}$, é também um infinito que se abre sobre sua Identidade e, com isso, para além de qualquer função (informativa, comunicativa), dá-se também como um lugar próprio ao abandono da reflexão, da interiorização e atribuição de causas. Cessa a perseguição das negativas dialéticas - que se interiorizam na inquietude da reflexão - e o pensamento é devolvido ao exterior.

A partir do momento, efetivamente, em que o discurso para de seguir a tendência de um pensamento que se interioriza e, dirigindo-se ao próprio ser da linguagem, devolve o pensamento para o exterior, ele é também e de uma só vez: narrativa meticulosa de experiência, de encontros de signos improváveis - linguagem sobre o exterior de qualquer linguagem, falas na vertente invisível das palavras; e atenção para o que da linguagem já existe, já foi dito, impresso, manifesto - escuta nấo tanto do que se pronunciou nele, mas do vazio que circula entre suas palavras, do murmúrio que não cessa de desfazê-lo, discurso sobre o não-discurso de qualquer linguagem, ficção do espaço invisível em que ele aparece. ${ }^{5}$

A voz que vem de fora, vem da linguagem por si mesma, a voz do carvalho, "linguagem rigorosa e fechada do aforismo, como nos fala na indistinção de uma palavra primeira" ${ }^{6}$, lê Blanchot em René Char, na, pelo poeta chamada, besta inominável" 
É o exterior aberto, desnudado, é o grito por saber que a poesia está "ligada a essa impossibilidade de pensar que é o pensamen-

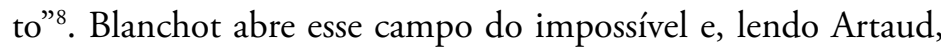
percebe que "ser é não ser, é essa falta do ser, falta viva que torna a vida desfalecente, inacessível e inexprimível, exceto pelo grito de uma feroz abstinência"'.

O grito, a declaração de existência de um Idêntico, de um absolutamente singular, da conjugaçáo de um ateísmo com a escritura (o nome de Deus, um nome sem conceito, que é chamado - por vezes como neutro - e, apenas como um Idêntico em não relação, para lembrar Deleuze, dá-se como uma outra experiência da linguagem: um experimentum linguae, diria, em outra clave, Giorgio Agamben), é também o clamor dessa "feroz abstinência", dessa ausência e afastamento ou ausentamento, como diz Jean-Luc Nancy, do sentido. Aliás, lembra o próprio Nancy a respeito de Blanchot:

$\mathrm{Na}$ conjunção do ateísmo e da escritura Blanchot reúne, no mesmo texto e no mesmo título, aquela do humanismo e do grito. O humanismo do grito seria o humanismo que abandona toda idolatria do homem e toda antropoteologia. Se não é exatamente no registro da escritura, também não é naquele do discurso - mas no do grito. Precisamente, "ele grita no deserto", escreve Blanchot. Não é por acaso que ele retoma uma fórmula insigne do profetismo bíblico. ${ }^{10}$

A exasperação de um sentido que se ausenta, a borda da e que é a linguagem (e Alejandra Pizarnik tocava essa borda afiada com seus pássaros: "Mas a ti quero olhar até que teu rosto se distancie de meu medo como um pássaro da borda afiada da noite"11), uma experiência patética (e mesmo ética) em que o pathos impossibilita ao eu-sujeito ${ }^{12}$ uma materialização inerte e ilusoriamente soberana.

Trata-se, mais do que do estado paroxístico em que o eu grita e se desgarra, de um sofrimento como indiferente, e não sofrido, e neutro (um fantasma de sofrimento), se aquele que está exposto a ele permanece despojado, justamente pelo sofrimento, desse "Eu" pelo qual padeceria. Assim é como o vemos: a marca de semelhante movimento consiste em que, pelo fato de o experimentarmos, escapa de nosso poder de experimentá-lo, e não é o que fica fora de experimentação, mas sim este algo de cuja experimentação já não podemos escapar. Experiência que alguém representará como estranha e, inclusive, como a experiência do estranhamento, porém, caso assim seja, reconhecemos que não o é, por estar muito distanciada: ao contrário do que está tâo perto que toda distância em relação a ela está proibida - estranha na mesma proximidade. ${ }^{13}$
8. BLANCHOT, Maurice. $O$ livro por vir, 2005, p. 51.

9. Ibidem, p. 53.

10. NANCY, Jean-Luc. "Le Nom de Dieu chez Blanchot", 2005, p. 133. Tradução nossa.

11. PIZARNIK, Alejandra. "Caminhos do Espelho (1962)". Revista Polichinello, 2014, p. 44.

12. "La renuncia al yo sujeto no es una renuncia voluntaria, por tanto tampoco es una abdicación involuntaria; cuando el sujeto se torna ausencia, la ausencia de sujeto o el morir como sujeto subvierte toda la frase de la existencia, saca el tiempo de su orden, abre la vida a la pasividad, exponiéndolo a lo desconocido de la amistad que nunca se declara.". Cf. BLANCHOT, Maurice. La escritura del desastre, 1987, p. 32.

13. BLANCHOT, Maurice. $E l$ Diálogo Inconcluso, 1993, p. 8889. Tradução nossa. 
14. ALIGHIERI, Dante. De Vulgari Eloquentia, 1986, s/p. Tradução nossa.

15. HELLER-ROAZEN, Daniel. Ecolalias. Sobre el olvido de las lenguas, 2005, p. 18. Tradução nossa.
A experiência da linguagem, do fora, do exterior, acontece nesse estranhamento: distância e proximidade que sufocam uma reflexão interior, um humanismo da palavra meditada, e o lançamento ao risco (ex periri: experiência sempre como exposição ao risco, à morte), ao grito que clama desde o deserto. Da exposição à morte, do lançar-se efetivamente à morte como uma abertura à linguagem (às línguas históricas), conta-nos Dante. No De vulgari eloquentia, fala sobre como as línguas históricas nascem após a expulsão do paraíso. Diz Dante:

Quanto à palavra que a voz do primeiro falante pronunciou pela primeira vez, é um ponto que náo hesito em considerar mais que claro para uma pessoa com a mente lúcida: foi o equivalente de "Deus", isto é, $E l$, dito em tom de pergunta ou de resposta. À razáo parece de fato absurdo e horrendo que o homem tenha nomeado algo antes de nomear Deus, tendo sido criado a partir Dele e por Ele. É portanto razoável que, como depois da transgressão cometida pelo gênero humano, todo homem comece a falar dizendo "ai", de modo que aquele que precedeu tal transgressão tenha, ao contrário, iniciado com alegria. ${ }^{14}$

O que Dante parece evocar é o fato de que, após a Queda, a linguagem humana só pode ter início por meio de um grito de dor e desespero (uma interjeiçáo, portanto, nem uma enunciação, nem uma pergunta ou uma designação). A marca da passagem entre eternidade e tempo histórico, assim, é o arruinar-se da língua alegre dos nomes em exclamação, no grito de dor, que assinala toda língua histórica. Não há volta ao mundo edênico dos nomes; a condenação é inexorável. E, na tradiçâo judaico-cristã, desde a primeira língua, a língua pré-babélica, qualquer tentativa humana de reencontro de uma língua dos nomes está condenada. Talvez seja por isso que Dante, no Canto XXXI do "Inferno", condene Nemrod - um dos gigantes descendentes de Noé, apresentado no Gênesis como um "valente caçador" [Gn. 10,9], e cujos sustentáculos de seu reino foram Babel, Arac e Acad [Gn. 10,10] e a quem a tradição atribui o projeto de construção da torre de Babel - à perda da linguagem significante. A condenação, entretanto, não é ao silêncio, mas à fala desarticulada, ao pronunciar glossolálico de sons que não produzem sentido. Na condição infernal, Nemrod perde a capacidade de uma voz articulada (a phoné enartros aristotélica) e, com isso, todo logos lhe é interdito; porém, não só a capacidade de articular a voz perde Nemrod. Podemos acrescentar que em sua condenação está também a perda da capacidade de gritar. Como sugere Daniel Heller-Roazen, a proposta dantesca de que as línguas históricas surgem de uma interjeição deve ser lida como uma condição da própria língua. Isto é, "assim como pode haver uma exclamação [...], pode haver uma língua [...]; uma língua na qual alguém não possa gritar absolutamente não seria uma língua humana"15. 
Não há senão a possibilidade do grito primeiro como marca original (um turbilhão; um salto do tigre constantemente presente, no melhor sentido benjaminiano; uma origem presente que não cessa de irromper), como traço na borda-linguagem.

Não é a voz que é a actualidade da fala, ela é sempre somente uma voz, a sua ou a minha, falante ou cantante, uma outra de cada vez. Está sempre partilhada, num certo sentido é a própria partilha. Uma voz começa aí onde começa o entrincheiramento de um ser singular. Mais tarde, com a sua fala, ele refará laços com o mundo, dará sentido ao seu próprio entrincheiramento. Mas primeiro, com a sua voz, clama um puro desvio, e isso não faz sentido.

- Toda a voz clama no deserto, como a do profeta. Aliás, é no deserto da existência desamparada, a braços com a falta e a ausência, que a voz se faz primeiramente ouvir. ${ }^{16}$

O grito do profeta na imensidáo do deserto como origem da palavra, como experiência original da língua, como a abertura ao mistério da língua. $\mathrm{Na}$ parte do fogo - esse resto insignificante em que a arte descobre sua soberania interior ${ }^{17}$-, nessa experiência do irrisório inapreensível e exterior, Blanchot, em um texto sobre Lautréamont, fala do mistério das letras. Parte de uma "evidência" de que a linguagem é feita de dois elementos distintos - "um material, sopro, som imagem escrita ou tátil, e o outro imaterial, pensamento, significado, sentimento" 18 - para propor uma ideia diversa da linguagem literária, que toque o fundo da dicotomia ao ponto de colocar os dois planos ressaltados como antagônicos (na proposição de Valéry "l'hésitation prolongée entre le sens et le son" ${ }^{19}$ ) em contato e, com isso, ver surgir o mistério da linguagem, seu silêncio que lhe dá suporte. Depois de várias conjecturas sobre análises abstratas da linguagem, nas quais um leitor a decomporia em elementos - justamente os dados materiais (o sopro que se torna palavra) e os imateriais (o sentido que se torna ideia) - para procurar uma relação entre ambos, Blanchot se depara com o limite de tal busca:

Os dois elementos que de início eram apenas fatores, isolados pela análise, mas não existindo à parte na realidade, tornaram-se agora partes autônomas da linguagem: o sopro é palavra, o sentido é idéia. Tudo se realizou na forma de fragmentos reais do discurso, que eram apenas constituintes abstratos do discurso. Mas, a partir do momento em que o lado material da linguagem se torna uma porção independente da linguagem, como o é uma palavra, compreendemos melhor que a passagem desse lado para o outro e, mais ainda, sua indiferenciação nessa passagem se tornem um escândalo ou pelo menos fenômenos bastante misteriosos exatamente o próprio mistério. ${ }^{20}$
16. NANCY, Jean-Luc. "Vox Clamans in Deserto". Cadernos de Leituras, 2013, p. 4.

17. PELLEJERO, Eduardo. Da morte da arte à hora dos assassinos. Texto no prelo, gentilmente cedido pelo autor.

18. BLANCHOT, Maurice. $A$ parte do fogo, 1997, p. 60.

19. VALÉRY, Paul. Oeuvres II, 1960, p. 637.

20. Ibidem, p. 60. 
21. Ibidem, p. 61.

22. Ibidem, p. 63.
O que está em jogo nas análises blanchotianas não é apenas uma dimensão estrutural da linguagem, mas a questão fundamental da linguagem literária, do encontro com uma dimensão em que o poeta (o escritor) coloque-se em jogo na linguagem, sinta o som (material) e o sentido (imaterial) suspendidos e, por isso, faça sua experiência fundamental da linguagem - uma experiência que ultrapassa uma dimensão puramente estética para ingressar numa instância ética. Continua Blanchot:

Mas talvez amedrontado pela vizinhança do mistério, nosso leitor agora o afaste depressa demais. Talvez esqueça o essencial. Náo estamos à procura de um mistério qualquer, mas do mistério nas Letras, e não de uma descrição qualquer da linguagem, mas dessa descrição requerida pela literatura. A literatura não é apenas a linguagem em repouso, a linguagem definitivamente feita, imobilizada e morta; é mais do que isso e, no entanto, é também unicamente isso, pois aspira ao paradoxo de uma língua que, construindo-se e como nascente, quisesse por isso mesmo ser definitivamente feita: ser perfeita. A linguagem da literatura não quer ser distinta da liberdade daquele que a fala e, ao mesmo tempo, quer ter a força de uma palavra impessoal, a existência de uma língua que se fala sozinha. Ela é uma coisa, uma natureza e a consciência que arruína tudo isto. ${ }^{21}$

O mistério a que Blanchot chama atenção, o mistério por excelência, é o mistério do mundo, da existência de algo, do sentido das coisas que só é dado pela linguagem, pelo nome de cada uma das coisas. Blanchot, que neste momento pensa os limites da literatura, vê o mistério da nomeação das coisas, não propriamente do dizer as coisas; o nome das coisas (o onoma dos gregos) é uma evidência, o que se dá a ver como e na linguagem e que, portanto, expóe as relaçóes internas à linguagem, apresentadas como mistério.

Mas é por ocasião da palavra que acontece o mistério e talvez como uma parte de não-linguagem, como a parte que na própria linguagem seria sempre estranha à linguagem e sua contradição sem fim, mas é também a partir desse fim que a linguagem fala melhor. O mistério está menos nessa não-linguagem do que na relação entre ele e a palavra, relação indeterminável, pois é nessa relação que a palavra se realiza e a não-linguagem, por sua vez, só aparece como uma linguagem simplesmente diferenciada, isto é, tal como as palavras devem descrevê-la para que a compreendamos, mas tal como ela náo pode ser, já que essas próprias palavras precisam dela para se fundirem na relaçáo que as forma. ${ }^{22}$

O mistério está na relação entre a não linguagem, essa pressuposição de um vazio para que possa haver linguagem, e a palavra; e esse calar-se mistérico, de fato, pode ser lido como 
a intransponibilidade dos elementos materiais e imateriais da linguagem, ou, da língua à fala (para falar com Benveniste).

Essa experiência da linguagem dirige-se, portanto, a um ponto que não é um fora da linguagem, mas a própria condição de possibilidade da linguagem, o fora que é a linguagem. Ou ainda, como alerta Jacques Derrida, "somente há borda, somente há limite na linguagem... Quer dizer, referência. Dado que nunca há nada a não ser referência, uma referência irredutível, pode-se também concluir que o referente - tudo, salvo o nome - é ou não é indispensável". ${ }^{23}$

A voz que clama no deserto é a mesma da viagem iniciática em que o poeta ingressa. Não é o inicio de nenhum mistério que não o próprio ingresso na palavra. Em tal viagem é como se a saída da infância e o ingresso na vida adulta então se tornassem também expressão do poeta como ser cindido, sempre em busca de um espaço original (khôra) para experimentar uma língua própria. Ou seja, o mistério das letras, o mistério da linguagem, não é uma impossibilidade da linguagem, um silêncio fora da linguagem, mas, justamente, a experiência desse fora.

Em um texto sobre o mito de Perséfone, Giorgio Agamben diz que a questão do silêncio que envolve o mistério dos iniciados - partindo da etimologia do termo mistério (myein, o fechar os olhos e sobretudo a boca no início dos ritos sagrados) - não dizia algo velado ao qual teriam acesso somente iniciados, mas um silêncio que dizia respeito aos próprios iniciados. Retomando os diálogos exotéricos perdidos de Aristóteles (transmitidos por Miguel Pselo), nos quais o estagirita traça uma distinção entre ensinamento (o que é gerado no homem a partir da escuta) e iniciação (quando o intelecto sofre - do verbo paschein, e daqui pathos - uma iluminaçáo), e os conectando com o De Anima e a Metafisica, ${ }^{24}$ o filósofo italiano explica que a diferenciação proposta por Aristóteles - na sua teoria da consciência - dá-se justamente porque paschein compreende dois significados: o primeiro, que diz respeito àquele que ainda está aprendendo, significa a destruição em ato de um princípio contrário (da potência de aprender anterior); o segundo diz respeito ao sujeito que já tem o hábito de um saber e que, mesmo tendo o saber em ato, conserva junto de si a potência de aprender que lhe é anterior ${ }^{25}$ (e, em certo sentido, o que é trazido à tona é o motivo da conservação da potência no ato de conhecimento). Assim, "os dois modos de acesso ao ato da theoria aqui descritos correspondem exatamente aos dois gêneros de conhecimento", ${ }^{26}$ quais sejam, ensinamento e iniciático.

Desse modo, Agamben interpreta a experiência mística em Elêusis como um êxtase do iniciado que, entretanto, não é um processo psíquico inexplicado, "mas uma visão análoga à theoria, ao conhecimento supremo do filósofo. Essencial, em ambos os casos, era que náo se tratava mais de um aprendizado, mas
23. DERRIDA, Jacques. Salvo o nome, 1995, p. 43.

24. Cf. AGAMBEN, Giorgio.

La Ragazza indicibile, 2010, p. 13-16.

25. ARISTÓTELES. De anima, 2006, p. 84.

26. AGAMBEN, Giorgio. La Ragazza indicibile, 2010, p. 14. Tradução nossa. 
27. Ibidem, p. 15.

28. Ibidem, p. 15.

29. WITTGENSTEIN,

Ludwig. Tractatus Lógico-

philosophicus, 1968, p. 128.

30. BACHMANN, Ingeborg. Il dicibile e l'indicibile, 2009, p. 64.

Tradução nossa.

31. Cf. VIRNO, Paolo.

Virtuosismo e revolução, 2008, p. 16-18.

32. AGAMBEN, Giorgio. Kommerell, o del Gesto, 1991, p. XIV. Tradução nossa. de um dar-se a si mesmo e um cumprir-se do pensamento". ${ }^{27}$ $\mathrm{O}$ acesso ao mistério concedido pelo iniciado é, desse modo, um tocar o silêncio do lugar do discurso. Agamben, tecendo considerações sobre a Metafisica aristotélica, conclui:

Na Metafísica (1051 b, 22-24), portanto, Aristóteles diz que, no conhecimento das coisas náo compostas, o verdadeiro consiste no thigein kai phanai, no 'tocar e nomear', explicando logo em seguida que a "nomeação" (phasis, o proferir palavras não ligadas na forma do juízo) não é a mesma coisa da "proposição" (kataphasis, dizer algo sobre algo). O conhecimento adquirido em Elêusis podia, portanto, ser expresso por meio de nomes, mas não por meio de proposiçóes; a "moça indizível" podia ser nomeada, mas não dita. Isto é, no mistério não havia espaço para o logos apophantikos (de interpr., 17b, 8), mas apenas para o onoma. E, no nome, acontecia algo como um "tocar" e um "ver". ${ }^{28}$

Aproximação de conhecimento e mistério, a partir do onoma, do nome: eis uma forma de experimentar o fora, a evidência do grito, a presença de uma classe de seres, para dizer com Deleuze. A língua que diz não pode ser dita, e o mundo que se abre pela linguagem permanece misterioso: pode-se dizer como é o mundo, mas isso não é dizer que o mundo é. A poeta Ingeborg Bachmann, em uma de suas emissōes radiofônicas da década de 60, ao comentar o aforismo 6.432 do Tractatus Logico-philosophicus de Wittgenstein - "Como é o mundo é perfeitamente indiferente para o que está além. Deus não se manifesta no mundo"29 - aproxima-o de Heidegger e apresenta, aí, uma espécie de dimensão da experiência da linguagem tangencial ao dizível e ao indizível:

Essa é a proposição mais amarga do Tractatus. Nela ressoa o verso de Hölderlin "Tão pouco de nós toca aos Olímpicos"; mas aqui se pretende dizer que Deus permanece o deus escondido, o deus absconditus, o qual não se mostra neste mundo para nós representável mediante um esquema formal. Se do mundo podemos falar, se, portanto, podemo-lo representar, se o dizível pode ser, então tudo isso pode ser somente graças ao indizível, ao Místico, ao limite - ou como quer que ser queira chamar. ${ }^{30}$

A poesia e a filosofia, na tradição ocidental, são espécies de tentativas de expor esse lugar da pressuposição; e essa tarefa só pode ser - assim como os místicos faziam ao experienciar o ingresso nessa escura zona da palavra, porém, sem as redençôes divinas - tentar dizer o indizível da linguagem. ${ }^{31}$ No entanto, no mundo contemporâneo, ao contrário da expectativa mística de ingresso na transcendência - cujo indizível seria o próprio Deus -, é de um mistério profano, "cujo único objeto é a própria existência", ${ }^{32}$ que se trata. 
Tal mistério profano é a mais banal ocupação do homem com uma palavra, esta que já não se prende ao seu fundamento silencioso (e, assim, metafísico). Nesse sentido, Jean-Luc Nancy, nos traços das Paixóes de Derrida, fala que no mistério não há um conteúdo de significados a ser revelado, mas infinito de sentidos que se abre nos nomes próprios e que retira a pergunta imediata que se faz diante do mistério - "o que isso quer dizer?" -, pois não há sentido último (uma espécie de verdade do ser), mas o infinito de sentidos do mundo aberto pela linguagem:

Nós aprendemos, precisamente, que não há um mistério que esperaria ser desvelado e que nos revelaria um sentido escondido. Não há um sentido último, mas há um "infinito do sentido", a fórmula foi pronunciada. Esse infinito do sentido não é nada que nós poderíamos tomar, nada que nós, tampouco, poderíamos figurar e, ainda menos, do qual poderíamos fazer para nós algo como um deus, para não falar de um ídolo. [...] É por isso que diante de um homem ou de uma mulher, obviamente, o que nós chamamos uma "pessoa", isto é, algo, se assim posso dizer, que está antes de tudo apresentado por um rosto e um nome - e o nome diz a verdade do rosto -, estou diante de uma singularidade, e é dessa singularidade que me diz algo o nome, o nome próprio. Ora o nome próprio, como sabemos pela boa linguística, não quer dizer nada, mesmo se é transferência de um nome comum. E somente o rosto, assim que ele me apresenta traços, aspectos, olhares, mostra-me também que não me entrega a intimidade da pessoa. E que talvez ela não pode ser entregue, significada. ${ }^{33}$

O olhar para as coisas - um olhar que é já sempre atravessado pela linguagem - revela o mundo, o infinito de sentidos das relaçóes singulares das coisas e nomes; revela nada mais do que a própria linguagem enquanto, novamente com Deleuze, um Idêntico. A linguagem chamada na grande extensão desse abismo exterior que é o deserto pelo grito.

É nesse sentido, creio, que a experiência do mistério é, no fundo, a experiência, ousaria dizer, mais comum. Ela é a experiência que acontece assim que nós não estamos ocupados com outra coisa - e "outra coisa" é evidentemente o que é sem mistério, que pode conter muitos supostos mistérios, isto é, de fato, segredos, coisas que não conhecemos, truques a serem encontrados, receitas a aprender, competências a manejar quando assim o podemos, se nós podemos. Mas isso que se produz sem cessar não é mistério. Melhor dizendo, não é concedido da manhã à noite, em cada minuto, encontrar-se diante do mistério sem segredo, mas isso se produz por momentos - se nisso prestamos atenção. E penso, além disso, que é muito simples e muito evidente dizer que, sem isso, nós não continuaríamos a viver numa humanidade tão difícil, que deixa a vida tão difícil. Nós continuamos porque sabemos algo do mistério de cada um,
33. NANCY, Jean-Luc.

"L'évidence du mystère", 2011, p. 84-85. Tradução nossa. 
34. Ibidem, p. 90-91.

35. NANCY, Jean-Luc. Ser singular plural, 2006, p. 102. Tradução nossa.

36. Algo próximo ao que Agamben, nos traços de Deleuze, diz ser a resistência enquanto criação: "Possiamo ora comprendere in modo nuovo la relazione fra creazione e resistenza di cui parlava Deleuze. Vi è, in ogni atto di creazione, qualcosa che resiste e si oppone all'espressione.

Resistere, dal latino sisto, significa etimologicamente 'arrestare, tener fermo' o 'arrestarsi'. Questo potere che trattiene e arresta la potenza nel suo movimento verso l'atto è l'impotenza, la potenzadi-non. La potenza è, cioè, un essere ambiguo, che non solo può tanto una cosa che il suo contrario, ma contiene in se stessa un'intima e irriducibile resistenza. Se questo è vero, dobbiamo allora guardare all'atto di creazione come a un campo di forze teso fra potenza e impotenza, potere e poter-non agire e resistere. L'uomo può avere signoria sulla sua potenza e aver acesso a essa solo attraverso la sua impotenza; ma - proprio per questo - non si dà, in verità, signoria sulla potenza ed essere poeta significa: essere in balia della propria impotenza.

Solo una potenza che può tanto la potenza che l'impotenza è allora la potenza suprema. Se ogni potenza è tanto potenza di essere che potenza di non essere, il passaggio all'atto può solo avvenire trasportando nell'atto la propria potenza-di-non. Ciò significa che, se a ogni pianist appartengono necessariamente la potenza di suonare e quella di non suonare, Glenn Gould è, però, solo colui che può non non suonare e, rivolgendo la sua potenza non solo all'atto ma alla sua stessa impotenza, suona, per così dire, con la sua potenza homem, animal, planta e do mistério deste mundo que nós transformamos sem cessar. Nós sabemos que é o mistério de um sentido infinito. ${ }^{34}$

Revelar o sentido de um mistério não é desvendar o ser por trás do significante linguístico, um absoluto - que poderia, inclusive, ser o Absoluto, o deus absconditus no mundo -, uma razão última que determinasse o sentido da revelação, pois

[...] tudo quanto existe é sua própria razão, não tem nenhuma outra, o que náo quer dizer que seja em si mesmo princípio e fim, já que não é "si mesmo". É sua própria dis-posição como pluralidade de singularidades. Esse ser se ex-póe então como o entre e como o com dos singulares. Ser, entre e com dizem a mesma coisa: dizem precisamente o que não pode mais que ser dito (o que se denominaria, por outro lado, "o inefável"), o que náo se pode apresentar como um ente entre outros, já que é o "entre" de todos os seres (entre: dentro, em meio de, com) que são todos e a cada vez uns entre outros. Ser não diz nada distinto e, em consequência, se o dizer diz sempre o ser de uma maneira ou outra, em troca o ser não se expóe mais do que no incorpório do dizer. $^{35}$

A experiência de uma evidência, portanto, é a experiência da linguagem para além de sua fundamentação enquanto instrumento apreendido e manejado no interior (em discursos reflexivos ou em atos comunicativos). É tocar essa evidência e maravilhar-se com o há linguagem. É, por fim, fazer da língua o lugar da experiência poética e, por certo, ética e política. Porém, tal experiência de maravilha - o experimentum linguae que é a poesia e também a ação política - é, de certo modo, uma resposta ao impossível (impossível este que, tomado enquanto impotência, pode ser lido como o ato de criação, a capacidade de resistir e experienciar esse fora ${ }^{36}$ ).

Nomeando o possível, respondendo ao impossível. Responder não consiste em formular uma resposta, de modo que se apazigue a pergunta que viria de modo obscuro de tal região. E consiste menos ainda em transmitir - ao estilo de um oráculo - alguns conteúdos de verdade de cujo conhecimento náo tivesse carecido o mundo da luz. Mas a existência da poesia, cada vez que é poesia, forma por si mesma resposta e, nessa resposta, é atenção ao que destina (desviando-se) na impossibilidade. Não a expressa, nem a diz, nem a atrai sob a fascinação da linguagem. Mas responde. Toda palavra inicial começa por responder. Resposta ao que todavia ainda não foi ouvido, resposta em si esperançada em que se afirma a espera impaciente do desconhecido e a esperança desejosa da presença. ${ }^{37}$ 
Ainda nas suas leituras de Artaud, Blanchot já apontava para esse grito de dor que, longe de um estado psíquico irrisório, é experiência e negação absoluta da separação vida/pensamento. A resposta ao impossível - desenhada com a pergunta: "Será que sofrer é, finalmente, pensar?” -, portanto, é o afrontamento desse pensamento doloroso do fora (o toque na borda da linguagem, a experiência de khora):

a impotência nunca é impotente o bastante, o impossível não é o impossível. Mas, ao mesmo tempo, o combate é também aquele que Artaud quer continuar, pois nessa luta ele não renuncia ao que chama de 'vida' (o jorro, a vivacidade fulgurante), cuja perda não pode tolerar, que quer unir a seu pensamento e que, por uma obstinaçáo grandiosa e horrível, se recusa a distinguir do pensamento. Ora, este não é mais do que a 'erosão' daquela vida, a 'emaciação' daquela vida, a intimidade de ruptura e de perda em que não há ida nem pensamento, mas o suplício de uma falta fundamental através da qual já se afirma a exigência de uma negação mais decisiva. E tudo recomeça. Pois Artaud nunca aceitará o escândalo de um pensamento separado da vida, nem mesmo quando está entregue à experiência mais direta e mais selvagem que jamais foi feita, da essência do pensamento entendida como separação, da impossibilidade que ela afirma contra ela mesma como o limite de sua potência infinita. ${ }^{38}$

A postulação da potência infinita justamente no lugar do impossível, na abertura e clivagem entre potência e impotência, na capacidade de resistir, com o grito, e, assim, criar. Não uma obra, mas uma contínua ação que mantém em si a dor dos possíveis e, no limite, desativa a linguagem tal qual apreendida na reflexão, na informação e na comunicação. A experiência coloca absolutamente em questão o dispositivo linguagem e, enquanto grito de criação, é a exposição da língua enquanto tal, enquanto um Idêntico: a coabitação do possível e do impossível no mesmo tabernáculo, é o eterno recomeço (a origem sempre presente - o salto) e a afronta entre potente e impotente, entre possível (que chama) e impossível (ao que se responde). Lembra Agamben que di non suonare. Di fronte all'abilità, che semplicemente nega e abbandona la propria potenza di non suonare, e al talent, che può soltanto suonare, la maestria conserva ed eserciga nell'atto non la sua potenza di suonare, ma quella di non suonare". Cf. AGAMBEN, Giorgio. "Che cos'è l'atto di creazione?”, 2014, p. 46-47.

37. BLANCHOT, Maurice. El Diálogo Inconcluso, 1993, p. 93-94.

38. Idem. O livro por vir, 2005, p. 55.

A potência-de-não não é uma outra potência ao lado da potência-de-: é sua inoperosidade, aquilo que resulta da desativação do esquema potência/ato. Ou seja, há um nexo essencial entre potência-de-não e inoperosidade. [...] $\mathrm{O}$ poder não cantar é, antes de mais, uma suspensão e uma exibição da potência de cantar que não transpassa simplesmente ao ato, mas se dirige a si mesma. Isto é, não há uma potência de não cantar que precede a potência de cantar e deve, portanto, anular-se para que a potência possa realizarse no canto: a potência-de-não é uma resistência interna à potência que impede que esta se exaure no ato e a leva a dirigir-se a si mesma, a fazer-se potentia potentiae, a poder a própria impotência. 
39. AGAMBEN, Giorgio. "Che cos'è l'atto di creazione?”, 2014, p. $52-53$.

40. BLANCHOT, Maurice. $L a$ Escritura del Desastre, 1987, p.

35.

41. Ibidem, p. 37.
A obra - por exemplo, Las Meninas - que resulta dessa suspensão da potência não representa apenas seu objeto: apresenta, junto deste, a potência - a arte - com a qual foi pintado. Assim a grande poesia náo diz somente o que diz, mas também o fato de que está dizendo, a potência e a impotência de dizê-lo. E a pintura é suspensão e exposição da potência do olhar, como a poesia é suspensão e exposição da língua. ${ }^{39}$

Em face do impossível - que nos exige resposta - a abertura aos possíveis (a contingência infinita do poder ou poder não); o fora e o grito denunciam, apelam, a língua. Há a suspensão e nada mais. O experimentum linguae - cuja forma basilar se dá na poesia, na suspensão e exposição da língua, a desativação do dispositivo linguagem - é ainda poder dizer, mesmo quando tudo parece já ter sido dito, mesmo quando o silêncio se avoluma no horizonte como a intempérie última aos viventes que falam. É ainda poder dizer sem a obrigação de fazê-lo, mas diante da impreterível potência de poder ou não fazê-lo (e o escrevente Bartleby, aqui, toma o posto de anunciador inequívoco dessa experiência, dessa exposição ao fora). É, por fim, ainda tomar em conta que "quando tudo está dito, o que resta por dizer é o desastre, ruína da fala, desfalecimento pela escritura, rumor que murmura: o que resta sem sobra (o fragmentário)" ${ }^{40}$ e, dessa maneira, perceber que "quando tudo se obscureceu, reina o esclarecimento sem luz que anunciam certas palavras." ${ }^{11}$ 


\section{Referências}

AGAMBEN, Giorgio. “Che cos'è l'atto di creazione?”. In: . Il Fuoco e il Racconto. Roma: Nottetempo, 2014.

Electa, 2010.

- La Ragazza indicibile. Mito e mistero di Kore. Milão:

. Kommerell, o del Gesto. In: KOMMERELL, M. Il

Poeta e l'indicibile. Tradução de Gino Giometti. Genova:

Marietti, 1991.

ALIGHIERI, Dante. De Vulgari Eloquentia. In: . Opere minori di Dante Alighieri. Tradução de Sergio Cecchin. Torino: UTET, v. 2, 1986. Disponível em: <http://www.classicitaliani. it/dante/prosa/vulgari_ita.htm\#_ftnref14>.

ARISTÓTELES. De anima. Tradução de Maria Cecília Gomes dos Reis. São Paulo: Ed. 34, 2006

BACHMANN, Ingeborg. Il dicibile e l'indicibile. Tradução de Barbara Agnese. Milão: Adelphi, 2009.

BLANCHOT, Maurice. A parte do fogo. Tradução de Ana Maria Scherer. Rio de Janeiro: Rocco, 1997 . El Diálogo Inconcluso. Tradução de Pierre de Place.

Caracas: Monte Avila Editores, 1993. . La escritura del desastre. Tradução de Pierre de Place.

Caracas: Monte Avila Editores, 1987. . O livro por vir. Tradução de Leyla Perrone-Moisés.

São Paulo: Martins Fontes, 2005.

. Une Voix Venue d'Ailleurs. Paris: Gallimard, 2002.

CAPRONI, Giorgio. A Coisa Perdida. Agamben comenta Caproni. BERNARDINI, Aurora Fornini (Org.). Tradução de Aurora Fornoni Bernardini. Florianópolis: EDUFSC, 2011.

DELEUZE, Gilles. A Dobra. Leibniz e o Barroco. Tradução de Luiz B. L. Orlandi. Campinas: Papirus, 1991.

DERRIDA, Jacques. Salvo o nome. Tradução de Nicia Adan Bonatti. Campinas: Papirus, 1995.

FOUCAULT, Michel. "O Pensamento do Exterior". In: . Ditos e Escritos. Vol. III. Estética: Literatura e Pintura;

Música e Cinema. MOTTA, Manuel Barros da(Org.). Tradução de Inês Autran Dourado Barbosa. Rio de Janeiro: Forense Universitária, 2009. 
HELLER-ROAZEN, Daniel. Ecolalias. Sobre el olvido de las lenguas. Tradução de Julia Benseñor. Buenos Aires: Katz Editores, 2005.

NANCY, Jean-Luc. "Lévidence du mystère". In: . Le Voyage Initiatique. Paris: Albin Michel, 2011.

."Le Nom de Dieu chez Blanchot". In: . $L a$

Déclosion. (Déconstruction du christianisme, 1). Paris: Galilée, 2005.

Ser singular plural. Traduçáo de Antonio Tudela Sancho. Madri: Arena Libros, 2006

"Vox Clamans in Deserto". Tradução de Fernanda Bernardo e Hugo Monteiro. Cadernos de Leituras. n. 13, p. 1-10, 2013. Disponível em: http://www.chaodafeira.com/wpcontent/uploads/2013/05/nancy.pdf

PELLEJERO, Eduardo. "Da morte da arte à hora dos assassinos." In: Perder por Perder (e outras apostas intelectuais). Texto no prelo, gentilmente cedido pelo autor.

PIZARNIK, Alejandra. "Caminhos do Espelho (1962)". Tradução de Vinícius Nicastro Honesko e Davi Pessoa. Revista Polichinello. n. 16, s/p, 2014.

VALÉRY, Paul. Oeuvres II. Paris: Gallimard, 1960.

VIRNO, Paolo. Virtuosismo e revolução. Tradução de Paulo Andrade Lemos. Rio de Janeiro: Civilização Brasileira, 2008.

WITTGENSTEIN, Ludwig. Tractatus Lógico-philosophicus. Tradução de José Arthur Giannotti. Sáo Paulo: Companhia Editora Nacional; USP, 1968. 